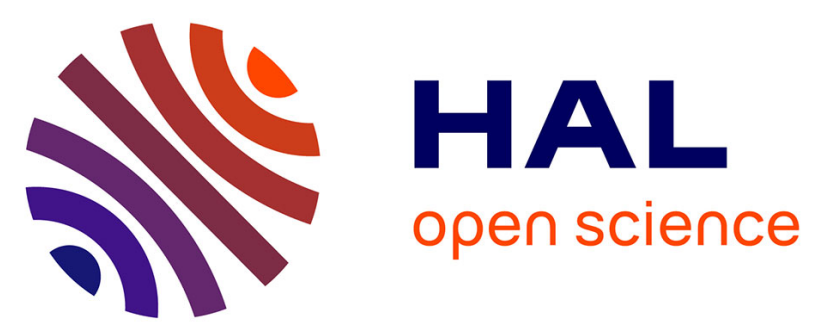

\title{
Elective late open conversion after EVAR is associated with comparable outcomes to primary open repair of abdominal aortic aneurysms
}

Robin Chastant, Ludovic Canaud, Baris Ata Ozdemir, Pierre Aubas, Nicolas Molinari, Eric Picard, Pascal Branchereau, Charles-Henri Marty-Ané, Pierre Alric

\section{To cite this version:}

Robin Chastant, Ludovic Canaud, Baris Ata Ozdemir, Pierre Aubas, Nicolas Molinari, et al.. Elective late open conversion after EVAR is associated with comparable outcomes to primary open repair of abdominal aortic aneurysms. Journal of Vascular Surgery, 2020, 73 (2), 10.1016/j.jvs.2020.05.033 . hal-02667678

\section{HAL Id: hal-02667678 https://hal.science/hal-02667678}

Submitted on 28 Jul 2021

HAL is a multi-disciplinary open access archive for the deposit and dissemination of scientific research documents, whether they are published or not. The documents may come from teaching and research institutions in France or abroad, or from public or private research centers.
L'archive ouverte pluridisciplinaire HAL, est destinée au dépôt et à la diffusion de documents scientifiques de niveau recherche, publiés ou non, émanant des établissements d'enseignement et de recherche français ou étrangers, des laboratoires publics ou privés. 


\title{
Elective late open conversion after endovascular aneurysm repair is associated with comparable outcomes to primary open repair of abdominal aortic aneurysms
}

Robin Chastant, MD, ${ }^{a}$ Ludovic Canaud, MD, PhD, ${ }^{a}$ Baris Ata Ozdemir, FRCS, PhD, ${ }^{a, b}$ Pierre Aubas, MD, ${ }^{c}$ Nicolas Molinari, MD, PhD, ${ }^{c}$ Eric Picard, MD, ${ }^{d}$ Pascal Branchereau, MD, ${ }^{d}$ Charles-Henri Marty-Ané, MD, PhD, ${ }^{a}$ and Pierre Alric, MD, PhD, ${ }^{a}$ Montpellier and Nimes, France; and Bristol, United Kingdom

\begin{abstract}
Objective: Three of four patients with infrarenal abdominal aortic aneurysm are now treated with endovascular aneurysm repair (EVAR). The incidence of secondary procedures and surgical conversions is increasing for a population theoretically unfit for open surgery. The indications and outcomes of late open surgical conversions after EVAR in a highvolume tertiary vascular unit are reported.
\end{abstract}

Methods: This retrospective single-center study includes all patients who underwent a late open conversion between January 1996 and July 2018. Data were collected from records on patient demographics, operative indications, surgical strategy, perioperative outcomes, and medium-term survival.

Results: Sixty-two consecutive patients (88.7\% male) with a mean age of 77.5 years are included. The median duration since index EVAR was 38.5 months; $65 \%$ of stent grafts requiring late open conversion had suprarenal fixation. Indications included $22.6 \%$ type IA, $16.1 \%$ type IB, and $45.2 \%$ type II endoleaks; $12.9 \%$ graft thrombosis; and $14.5 \%$ endoprosthesis infection. Complete endograft explantation was performed in $37.1 \%$ of patients and a partial explantation in $54.8 \%$, whereas $8.1 \%$ of stent grafts were wholly preserved in situ. Overall 30-day mortality was $12.9 \%(n=8)$ in the cohort and $2.7 \%$ for elective patients. The all-cause morbidity rate was 40.1\%, and the median length of hospital stay was 9 days. After follow-up of 28.4 months (range, 1.8-187.3 months), all-cause survival was 58.8\%. Avoidance of aortic clamping $(P=.006)$ and elective procedures $(P=.019)$ were associated with a significant reduction in the length of hospital stay. Moreover, the 30-day mortality $(P=.002)$, occurrence of postoperative renal dysfunction $(P=.004)$, and intestinal ischemia $(P=.017)$ were increased in the emergency setting. Excluding cases with rupture or infection, survival estimates were $97 \%$, $97 \%$, and $71 \%$ at 1 year, 2 years, and 5 years, respectively.

Conclusions: Technically more complex than primary open surgery, late open conversion is a procedure that generates an acceptable perioperative risk when it is performed in a high-volume aortic surgical center. Elective open conversion is associated with excellent early and late outcomes. Endograft preservation strategies decrease perioperative morbidity.

Keywords: Abdominal aortic aneurysm; Open surgical repair; Endovascular aneurysm repair; Late open conversion; Delayed stent graft explantation

The technical evolution of stent grafts has resulted in the technical suitability of most infrarenal abdominal aortic aneurysms (AAAs) for either standard or complex endovascular exclusion. Although endovascular aneurysm repair (EVAR) is associated with low perioperative mortality and morbidity, the midterm and long-term consequences of EVAR have resulted in an increasing number of cases undergoing secondary procedures and late open surgical conversions. 'A late open conversion requires the use of specific strategies and techniques in patients who were previously assessed as less suitable for open repair. Endoleak, with a prevalence of $30 \%$, is the main predictor of postEVAR reintervention. ${ }^{2}$ Societal guidelines recommend early management and careful monitoring. ${ }^{3}$ This study details

\footnotetext{
From the Department of Thoracic and Vascular Surgery, and Department of Medical Information. ${ }^{c}$ Arnaud de Villeneuve Hospital. Montpellier; the Vascular and Endovascular Department, North Bristol NHS Trust and University of Bristol, Bristol ${ }^{\text {; }}$; and the Department of Vascular and Thoracic Surgery, Caremeau Hospital, Nimes. ${ }^{d}$ Author conflict of interest: none.
} 
the single-center experience of an aortic unit in managing patients requiring late open conversion after EVAR.

\section{METHODS}

Data records. Late open conversion was defined as open surgical repair of infrarenal AAA occurring $>30$ days after EVAR. Patients to be included were identified by screening of physical and electronic operating room log books, with the assistance of clinical coders from the Department of Medical Information. Data collection and analysis were retrospective, using paper records and electronic records thereafter. To ensure an accurate follow-up of each patient, postoperative consultation letters were obtained, and either the patient or the patient's general practitioner was contacted by phone.

This study was approved by the Local Committee for Research Ethics of the university hospital center and declared compliant by the Comité National Français de I'Informatique et des Libertés. Individual patient consent was waived for inclusion in the study.

Patients. Demographic data included age, sex, comorbidities (cardiovascular risk factors, coronary heart disease, arrhythmia, heart failure, chronic respiratory failure, chronic renal failure, body mass index, history of abdominal surgery), and use of an antiplatelet or anticoagulant treatment. The American Society of Anesthesiologists class reported was determined by specialized cardiovascular anesthetists.

The EVAR implantation date, location, device, and anatomic characteristics as well as presence or absence of early endoleak were recorded. The main indication for and urgency, surgical strategy, and technical details of late open conversion were determined.

Operative strategy. Partial explantations for type I or type III endoleaks were performed whenever possible to avoid extensive dissection and the potential morbidity. The whole endograft was preserved when the indication for conversion was an isolated type II endoleak. Nevertheless, interventions were adapted according to intraoperative findings and the perceived reliability of the endoprosthesis components left in situ. Total explantation was advocated in case of sepsis and aortoenteric fistula.

End points. The primary end point was postoperative mortality at 30 days. Secondary end points were perioperative morbidity, acute kidney injury (AKI), length of stay in critical care, length of hospital stay, and long-term survival.

AKI was considered significant when the serum creatinine concentration was higher than twice its initial value, sudden in onset (1-7 days), and persistent for $>24$ hours, in association with oliguria (diuresis $<0.5 \mathrm{~mL} / \mathrm{kg} / \mathrm{h}$ during at least 12 hours), or when temporary or permanent hemodialysis was required. These criteria correspond to the Injury stage of the Risk, Injury, Failure, Loss of kidney

\section{ARTICLE HIGHLIGHTS}

Type of Research: Single-center, retrospective cohort study

Key Findings: Among 62 late open conversions after endovascular aneurysm repair, 30-day mortality was significantly higher in urgent or emergent procedures compared with elective ( $25 \%$ vs $2.9 \%$ ). Urgent or emergent cases had significantly increased rates of postoperative renal dysfunction, longer critical care and hospital stays, and higher midterm mortality. Suprarenal fixation was not associated with significant differences in outcomes. Excluding rupture and infection, survival estimates were 97\%, 97\%, and $71 \%$ at 1 year, 2 years, and 5 years, respectively.

Take Home Message: Elective late open conversion is a safe and reliable strategy with outcomes comparable to primary repair; thus, endoleaks must be detected and appropriately managed to reduce the risk of rupture.

function, and End-stage (RIFLE) classification and to stage 2 of the Kidney Disease Outcomes Quality Initiative ${ }^{4}$ classification.

Each patient was clinically reviewed in a postoperative period of 3 to 6 months after late open conversion. Within this time frame, all patients underwent arterial duplex ultrasound examination of the aorta and lower limbs, supplemented by contrast material injection after partial or complete graft preservation to detect endoleaks. If doubt remained, computed tomography angiography was performed.

Statistics. Statistical analysis was performed using SAS statistical software version 9 (SAS Institute, Cary, NC). The threshold of statistical significance was set at $P<.05$. Differences between subgroups were assessed using mean comparison tests (Student or Wilcoxon as a function of the distribution) for quantitative variables and either the $\chi^{2}$ or Fisher exact test for the qualitative variables. Kaplan-Meier methodology was used to estimate survival probabilities. Results are expressed as means or medians for continuous variables and as frequency and percentages for categorical variables.

\section{RESULTS}

Demographics. Sixty-two consecutive patients underwent late open conversion between January 1996 and July 2018. Fifty-five patients were male $(88.7 \%)$, and the mean age was $77.5 \pm 8.7$ years. Complete patient demographic data and comorbidities are presented in Supplementary Table I (online only). Mean aneurysm size was $71.3 \pm 21.9 \mathrm{~mm}$. The median time from the index EVAR procedure to late open conversion was 38.5 months (range, 4.5-132 months). 
Indications. Late open conversion was required in most cases secondary to endoleaks (72.5\%) but also for stent graft thrombosis (12.9\%) and infection (14.5\%). Of the 45 patients with endoleak as the indication, 14 had type IA, 9 had type IB, 28 had type II, and 6 had type III endoleaks and 2 had endotension (13 patients had more than one demonstrable endoleak type). Twenty patients (32\%) had previously undergone one or more (range, 1-3) endovascular procedures before late open conversion. Fourteen of these procedures were one or more attempted embolizations for endoleak, whereas six involved the implantation of additional stent grafts. Mean time to late open conversion after the last secondary endovascular procedure was 15.5 months (range, 570.5 months).

Of these cases, $4.8 \%$ (3) had an acute infection with sepsis, $6.5 \%(4)$ a persistent chronic infection, and $3.2 \%$ (2) an aortoenteric fistula. Twelve late open conversions (19.4\%) were performed in a life-threatening emergency including AAA rupture and septic shock associated with graft infection or aortoenteric fistula (emergency group), requiring immediate surgery. Urgent status (16 [25.8\%]) was assigned to those whose clinical condition permitted surgical conversion beyond 24 hours (urgent group). These consisted mainly of intact symptomatic aneurysms, lower limb ischemia with Rutherford class I or Ila status, and infection without evidence of septic shock. Thirty-four (54.8\%) procedures were performed electively.

The stent grafts were generally bifurcated in 56 (90\%) and included suprarenal fixation in 40 (65\%). The devices requiring reintervention were Zenith (Cook Medical, Bloomington, Ind) in 21 cases (34\%), Excluder (W. L. Gore \& Associates, Flagstaff, Ariz) in 17 (27\%), Endurant (Medtronic, Santa Rosa, Calif) in 9 (15\%), Talent (Medtronic) in 7 (11\%), Anaconda (Vascutek, Terumo, Inchinnan, Scotland, United Kingdom) in 2 (3\%), and first-generation stent graft in $3(5 \%)$. The make of the endograft could not be determined for three patients from the records available.

Operative management. A retroperitoneal approach was used in 13 patients (21\%) and minilaparotomy (up to $8 \mathrm{~cm})^{5}$ in six (10\%). The remainder (43 [69.4\%]) of the procedures were transperitoneal. Proximal aortic crossclamping was supraceliac in 7 (11.3\%), supramesenteric in 1 (1.6\%), suprarenal in 16 (25.8\%), and infrarenal in 29 (46.8\%). The aortic clamp time was not recorded in 10 patients. The mean total aortic clamp time was $23.5 \mathrm{mi}-$ nutes above the renal arteries and 44.9 minutes below the renal arteries. In cases of multiple endoleaks, crossclamping was needed for partial or total explantation. In case of an isolated type II endoleak, a sacotomy was preferred with ligature of the target collateral artery without clamping. Aortic clamping was also not required in five patients $(8.1 \%)$ because vascular reconstruction was not required (Table I). Owing to the wide distribution of clamp level (supraceliac, supramesenteric, suprarenal,
Table I. Operative characteristics

\begin{tabular}{|c|c|}
\hline \multicolumn{2}{|l|}{ Aortic clamping } \\
\hline Supraceliac & $7(11.3)$ \\
\hline Supramesenteric & $1(1.6)$ \\
\hline Suprarenal & $16(25.8)$ \\
\hline Inter-renal & $3(4.8)$ \\
\hline Infrarenal & $29(46.8)$ \\
\hline Single limb & $1(1.6)$ \\
\hline No clamp & $5(8.1)$ \\
\hline Aortic occlusion balloon & $\mathrm{O}(0)$ \\
\hline \multicolumn{2}{|l|}{ Clamping duration, minutes } \\
\hline Suprarenal clamping ${ }^{a}$ & 23.5 \\
\hline Infrarenal clamping ${ }^{b}$ & 44.9 \\
\hline \multicolumn{2}{|l|}{ Explantation } \\
\hline Complete explantation & $23(37.1)$ \\
\hline Partial explantation & $34(54.8)$ \\
\hline Proximal fixation preservation & $17(27.4)$ \\
\hline Limb preservation & $9(14.5)$ \\
\hline $\begin{array}{l}\text { Proximal fixation and limb } \\
\text { preservation }\end{array}$ & $8(12.9)$ \\
\hline $\begin{array}{l}\text { Complete in situ stent graft } \\
\text { preservation }\end{array}$ & $5(8.1)$ \\
\hline \multicolumn{2}{|l|}{ Vascular reconstruction } \\
\hline Aortoaortic tube & $19(30.6)$ \\
\hline Aortobi-iliac & $32(51.6)$ \\
\hline Aortofemoral or complex & $6(9.7)$ \\
\hline Sacotomy with graft salvage & $5(8.1)$ \\
\hline \multicolumn{2}{|c|}{$\begin{array}{l}\text { Categorical variables are presented as number (\%). Continuous vari- } \\
\text { ables are presented as means. } \\
\text { a Twenty-four patients. } \\
\text { bSix patients did not undergo clamping; } 10 \text { patients with missing or } \\
\text { imprecise data. }\end{array}$} \\
\hline
\end{tabular}

inter-renal, infrarenal, single limb) and the variable recording of cross-clamping time in the early patients in this series, safe conclusions on the consequences of aortic clamp position cannot be reported. Median and mean operative times were, respectively, 146 and 160 minutes. Complete preservation of the endograft significantly reduced the operative time (89 minutes vs 146 minutes [partial explantation] and 166 minutes [total explantation]; $P=.002$ ), length of stay ( 6 days vs 9 days vs 10.5 days; $P=.006$ ), and transfusion requirements ( $O$ unit vs 2.9 units vs 5.1 units; $P=.011$; Table $\|$ ) and was not associated with changes in mortality. When vascular reconstruction was required, the chosen vascular substitutes were mainly prosthetic (48 [77.4\%]), and in cases of infection, arterial allograft (7 [11.3\%]) and physicianmade xenopericardial grafts were used (2 [3.2\%]).

Morbidity and 30-day mortality. The median length of stay in critical care was 2 days (mean, 3.9 days). The median total hospital stay was 9 days (mean, 13.5 days). Five patients $(8.1 \%)$ developed intestinal ischemia 
Table II. Comparison according to type of explantation

\begin{tabular}{|c|c|c|c|c|}
\hline Variable & $\begin{array}{l}\text { No explantation } \\
(n=5)\end{array}$ & $\begin{array}{l}\text { Partial explantation } \\
\quad(\mathrm{n}=34)\end{array}$ & $\begin{array}{l}\text { Total explantation } \\
(\mathbf{n}=23)\end{array}$ & $P$ value \\
\hline \multicolumn{5}{|c|}{ Perioperative and early postoperative data ( $<48$ hours) } \\
\hline Operative time, minutes & 89 & 146 & 166 & .002 \\
\hline Perioperative bleeding, $\mathrm{mL}$ & 950 & 1788 & 2684 & .180 \\
\hline Early transfusion, PRBC units & 0 & 2.6 & 3.9 & 019 \\
\hline \multicolumn{5}{|l|}{ Urinary output ${ }^{\mathrm{a}}$} \\
\hline Preserved & $5(100)$ & $17(53.1)$ & $13(59.1)$ & .294 \\
\hline Oliguria or anuria & 0 & $13(40.6)$ & 9 (40.9) & \\
\hline Serum creatinine, ${ }^{b} \mathrm{mmol} / \mathrm{L}$ & 108 & 125 & 129 & .660 \\
\hline Hemoglobin, g/dL & 11.9 & 10.2 & 9.4 & .037 \\
\hline \multicolumn{5}{|l|}{ General postoperative data } \\
\hline Early mortality ( $<30$ days) & 0 & $6(17.7)$ & $2(8.7)$ & .507 \\
\hline Length of hospital stay, days & 6 & 9 & 10.5 & .006 \\
\hline Length of stay in critical care, days & 1 & 2 & 2 & .129 \\
\hline Total transfusion, PRBC units & 0 & 2.9 & 5.1 & .011 \\
\hline Maximal serum creatinine, ${ }^{b} \mathrm{mmol} / \mathrm{L}$ & 123 & 149 & 166 & .537 \\
\hline$A K I^{a}$ & 0 & $13(41.9)$ & $9(39.1)$ & .254 \\
\hline Acute hemodialysis $^{b}$ & 0 & $1(3.1)$ & $2(8.7)$ & .667 \\
\hline Retroperitoneal hematoma & 0 & $5(14.7)$ & $3(13.0)$ & 1 \\
\hline Acute limb ischemia & 0 & 0 & $1(4.4)$ & .452 \\
\hline Intestinal ischemia & 0 & $3(8.8)$ & $2(8.7)$ & 1 \\
\hline Reoperation & 0 & $5(14.7)$ & $3(13.0)$ & 1 \\
\hline Survival at follow-up ${ }^{c}$ & $5(100)$ & $15(51.7)$ & $10(58.8)$ & .122 \\
\hline \multicolumn{5}{|c|}{$\begin{array}{l}\text { AKI, Acute kidney injury (evaluation of acute renal dysfunction according to Risk. Injury. Failure. Loss of kidney function, and End-stage [RIFLE] and } \\
\text { Kidney Disease Outcomes Quality Initiative classifications): PRBC, packed red blood cell. } \\
\text { Categorical variables are presented as number (\%). Continuous variables are presented as mean or median. Boldface } P \text { values represent statistical } \\
\text { significance. } \\
\text { a Five patients are excluded because of chronic hemodialysis or early death. } \\
\text { bThree patients are excluded because of chronic hemodialysis. } \\
\text { 'There were } 21 \text { deaths, } 30 \text { survivals, and } 11 \text { lost to follow-up. }\end{array}$} \\
\hline
\end{tabular}

postoperatively, all of whom had undergone emergency procedures. Four required partial or total colectomy; one patient died on the third postoperative day, and another with acute lower limb ischemia required iliofemoral thrombectomy. Eight patients (12.9\%) had postoperative bleeding complications but only three required surgical reintervention. A total of eight patients (12.9\%) underwent at least one revision operation after late open conversion. Twenty-two patients (37.3\%) had postoperative $\mathrm{AKI}$, three of whom (5.1\%) required temporary hemodialysis (Table III).

Overall, eight patients (12\%) died within 30 days of operation (Supplementary Table II, online only). The mean age of this group was 8 years older than those who survived the perioperative period ( 84.5 vs 76.5 years).

Of the stent grafts with suprarenal fixation, $72.5 \%$ underwent partial graft preservation compared with $22.7 \%$ of those with infrarenal fixation. The presence of suprarenal fixation was not associated with significant differences in outcome including the duration of surgery (149 vs 138 minutes; $P=.394$ ), 30-day mortality (15\% vs
9.1\%; $P=.700$ ), total transfusion (3.6 vs 3.2 packed red blood cell units; $P=.324$ ), postoperative AKI (36.4\% vs $37.8 \% ; P=.909$ ), and survival at follow-up (68.4\% vs $53.1 \% ; P=.283$ ).

The risk of bleeding was increased in infective cases because of local inflammation, technical difficulty, and prolongation of the procedure, with an increased erythrocyte transfusion requirement during hospitalization (6.2 units vs 2.9 units; $P=.026$ ) and extended operative time (200 minutes vs 134 minutes; $P=.008$ ). Although there is a trend toward an increased rate of surgical revision in patients with endograft infection $(33.3 \%$ vs $9.4 \%$; $P=.083)$, no differences in morbidity or postoperative mortality were identified.

The 30-day mortality was significantly higher in urgent or emergency procedures $(P=.002)$, with only one death $(2.9 \%)$ in the elective patients and seven $(25 \%)$ in the nonelective patients (Table IV). This population also had a significantly higher rate of postoperative renal dysfunction $(P=.004)$, critical care stay $(P=.002)$, and hospital stay $(P=.019)$. 
Table III. Results in the whole cohort $(\mathrm{N}=62)$

\begin{tabular}{|c|c|}
\hline \multicolumn{2}{|c|}{ Perioperative and early postoperative data ( $<48$ hours) } \\
\hline Operative time, minutes & $146(61-486)$ \\
\hline Extubation, days & $0(0-2)$ \\
\hline Perioperative bleeding, $\mathrm{mL}$ & $2135(450-5750)$ \\
\hline Blood autotransfusion, $\mathrm{mL}$ & $689(0-2450)$ \\
\hline Early transfusion, PRBC units & $2.8(0-14)$ \\
\hline \multicolumn{2}{|l|}{ Urinary output $^{\mathrm{a}}$} \\
\hline Preserved & $35(61.4)$ \\
\hline Oliguria or anuria & $22(38.6)$ \\
\hline Serum creatinine, ${ }^{b} \mathrm{mmol} / \mathrm{L}$ & $125(51-247)$ \\
\hline Hemoglobin, g/dL & $10(5-15.5)$ \\
\hline \multicolumn{2}{|l|}{ General postoperative data } \\
\hline Early mortality (<30 days) & 8 (12.9) \\
\hline Length of hospital stay, days & $9(1-71)$ \\
\hline Length of stay in critical care, days & $2(0-71)$ \\
\hline Total transfusion, PRBC units & $3.4(0-16)$ \\
\hline Maximal serum creatinine, ${ }^{b} \mathrm{mmol} / \mathrm{L}$ & $153(85-492)$ \\
\hline$A K I^{a}$ & $22(37.3)$ \\
\hline Acute hemodialysis ${ }^{b}$ & $3(5.1)$ \\
\hline Acute coronary syndrome & 0 \\
\hline Retroperitoneal hematoma & 8 (12.9) \\
\hline Acute limb ischemia & $1(1.6)$ \\
\hline Intestinal ischemia & $5(8.1)$ \\
\hline Reoperation & 8 (12.9) \\
\hline Follow-up period, months & $28.4(1.8-187.3)$ \\
\hline Survival at follow-up ${ }^{c}$ & $30(58.8)$ \\
\hline \multicolumn{2}{|c|}{$\begin{array}{l}\text { AKI, Acute kidney injury (evaluation of acute renal dysfunction ac- } \\
\text { cording to Risk, Injury. Failure, Loss of kidney function, and End-stage } \\
\text { [RIFLE] and Kidney Disease Outcomes Quality Initiative classifica- } \\
\text { tions): PRBC, packed red blood cell. } \\
\text { Categorical variables are presented as number (\%). Continuous vari- } \\
\text { ables are presented as mean (range) or median (range). } \\
\text { a Five patients are excluded because of chronic hemodialysis or early } \\
\text { death. } \\
\text { bThree patients are excluded because of chronic hemodialysis. } \\
{ }^{\text {c} T h e r e ~ w e r e ~} 21 \text { deaths, } 30 \text { survivals, and } 11 \text { lost to follow-up. }\end{array}$} \\
\hline
\end{tabular}

Late-term survival. The mean follow-up was 28.4 months with a rate of survival of $58.8 \%$.

During the study period, 21 patients died and 11 were lost to follow-up. Overall survival estimates for the whole cohort were $78 \%$ (68\%-89\%) at 1 year, $73 \%$ (62\%-86\%) at 2 years, and $49 \%$ (33\%-73\%) at 5 years. Medium-term mortality in patients undergoing emergent or urgent surgery was significantly increased (hazard ratio, 6 [2.2-17]; $P<.001)$. Excluding those with rupture or infection, survival estimates were 97\% (92\%-100\%) at 1 year, 97\% (92\%-100\%) at 2 years, and $71 \%(48 \%-100 \%)$ at 5 years (Fig).

\section{DISCUSSION}

With 62 patients included, this series is, to the best of our knowledge, the fourth largest single-center cohort study of this topic. The first study reporting open surgical conversions after endovascular repair, published in 1997 by May et al, ${ }^{6}$ reported $11.5 \%$ early and $4.4 \%$ late conversion rates. The European Collaborators on Stent/graft Techniques for Aortic Aneurysm Repair (EUROSTAR) ${ }^{7}$ registry in 2000 highlighted a cumulative conversion risk of $2.1 \%$ per year, mainly related to proximal or distal type I endoleak, type II and type III endoleak, stent migration, and kinking. In 2009, the Cleveland Clinic $^{8}$ reported no difference in perioperative morbidity and mortality according to the presence or absence of suprarenal fixation or the level of aortic clamping. Five years later, in a total cohort of 100 patients, the same center ${ }^{9}$ reported a significant increase in 30-day mortality when clamping was supraceliac, in an infectious context, or during emergent procedures.

The extent of endograft explantation depended on a variety of factors, including suprarenal fixation and infection. This study demonstrates improved morbidity with a graft preservation strategy. Some groups recommended total explantation preferentially, ${ }^{8}$ whereas others reported better results if the stent graft is partially preserved. ${ }^{10}$ In this series, partial explantation was performed in $55 \%$ of the cases, with an observed reduction in operative time and hemorrhagic consequences. Although neither the 30-day mortality nor length of hospital stay is significantly reduced, partial explantation does not appear to be associated with higher rates of stent migration or stent fracture at $>2$ years of followup." A partial explantation of the stent graft was preferred where possible, maintaining the suprarenal anchorage, a part of the body, or limbs. This reduces complications inherent to an extensive dissection, injuries from removal of stents with barbs, and increased operative time.

Nevertheless, rigorous surveillance after partial explantation is considered essential, like after the index EVAR. This avoids a rupture relative to an endoleak ${ }^{12}$ or iliac aneurysmal evolution after graft limb removal. ${ }^{13}$ With the approach described in this series, no ruptures were observed in this subgroup of patients. As reported in the series of Scali et al, ${ }^{14}$ it can be concluded that open conversion will become more common as oldergeneration EVAR devices fail and with the widespread stent graft use in anatomically complex patients.

Despite more accurate EVAR technology now, many type I endoleaks are not easily treated with additional endograft pieces, so the use of late open conversion in this indication is still important, especially when these open procedures do not increase morbidity and mortality.

Regarding isolated type II endoleaks, the decision tree presented in the study of Mangialardi et $\mathrm{al}^{15}$ is useful. Open conversion is recommended, preferentially with complete graft preservation, for a patient in good general condition with a persistent isolated type II endoleak and an increasing aneurysmal size $>5 \mathrm{~mm}$ during the followup for which no endovascular treatment has been effective. 
Table IV. Comparison according to level of emergency

\begin{tabular}{|c|c|c|c|c|}
\hline Variable & Elective $(n=34)$ & Urgent $(n=16)$ & Extreme emergency $(n=12)$ & $P$ value \\
\hline \multicolumn{5}{|c|}{ Perioperative and early postoperative data ( $<48$ hours) } \\
\hline Operative time, minutes & 126 & 152 & 174 & .213 \\
\hline Perioperative bleeding, $\mathrm{mL}$ & 1621 & 1880 & 4700 & .078 \\
\hline Early transfusion, PRBC units & 1.5 & 3.5 & 5,6 & $<.001$ \\
\hline \multicolumn{5}{|l|}{ Urinary output $^{a}$} \\
\hline Preserved & $22(70.9)$ & $9(56.3)$ & $4(33.3)$ & .121 \\
\hline Oliguria or anuria & $8(25.8)$ & $7(43.8)$ & $7(58.3)$ & \\
\hline Serum creatinine, ${ }^{\mathrm{b}} \mathrm{mmol} / \mathrm{L}$ & 111 & 144 & 141 & .027 \\
\hline Hemoglobin, g/dL & 10.2 & 9.7 & 9.9 & .430 \\
\hline \multicolumn{5}{|l|}{ General postoperative data } \\
\hline Early mortality ( $<30$ days) & $1(2.9)$ & $2(12.5)$ & $5(41.7)$ & .002 \\
\hline Length of hospital stay, days & 6 & 9 & 9 & .019 \\
\hline Length of stay in critical care, days & 1 & 2 & 5 & .002 \\
\hline Total transfusion, PRBC units & 1.7 & 5.1 & 6.1 & $<.001$ \\
\hline Maximal serum creatinine, ${ }^{b} \mathrm{mmol} / \mathrm{L}$ & 131 & 189 & 167 & .089 \\
\hline $\mathrm{AKI}^{\mathrm{a}}$ & $7(21)$ & $11(68.8)$ & $4(40)$ & .004 \\
\hline Acute hemodialysis ${ }^{b}$ & 0 & $2(12.5)$ & $1(9.1)$ & .085 \\
\hline Intestinal ischemia & 0 & $3(18.8)$ & $2(16.7)$ & .018 \\
\hline Acute limb ischemia & 0 & $1(6.25)$ & $\mathrm{O}$ & .452 \\
\hline Retroperitoneal hematoma & $3(8.8)$ & $2(12.5)$ & $3(25)$ & .356 \\
\hline Reoperation & $2(5.9)$ & $3(18.8)$ & $3(25)$ & .148 \\
\hline Survival at follow-up & $22(81.5)$ & $6(42.9)$ & $2(20.0)$ & $<.001$ \\
\hline \multicolumn{5}{|c|}{$\begin{array}{l}\text { AKI. Acute kidney injury (evaluation of acute renal dysfunction according to Risk, Injury, Failure, Loss of kidney function, and End-stage [RIFLE] and } \\
\text { Kidney Disease Outcomes Quality Initiative classifications); PRBC, packed red blood cell. } \\
\text { Categorical variables are presented as number (\%). Continuous variables are presented as mean or median. Boldface } P \text { values represent statistical } \\
\text { significance. } \\
\text { a Five patients are excluded because of chronic hemodialysis or early death. } \\
\text { bThree patients are excluded because of chronic hemodialysis. } \\
\text { cThere were } 21 \text { deaths, } 30 \text { survivals, and } 11 \text { lost to follow-up. }\end{array}$} \\
\hline
\end{tabular}

The systematic attempt for complete in situ preservation of the endografts is recommended by several authors. Positive results at $>3$ years of follow-up ${ }^{15,16}$ encourage recommendation of this approach to type II endoleaks that are refractory to complementary endo vascular treatments. Five patients $(8.1 \%)$ in this series benefited from this strategy, significantly reducing the operative time and the bleeding consequences. This unit's systematic practice is to prepare proximal clamp sites even when complete endograft preservation is planned in case of failure of this strategy intraoperatively. Proximal aortic occlusion balloons were not used because surgical control of the supraceliac aorta is fast, straightforward, and reliable, particularly for elective or emergency cases with intact aneurysms. In this context, the aortic occlusion balloon adds little to the procedure. On the other hand, distal iliac control using occlusive balloons was frequent.

With a duration longer than 190 minutes, open surgical conversion is in most centers a significantly longer pro cedure than primary open repair ${ }^{14,17-19}$ because of stentrelated inflammation and the frequently required extensive dissection. In this series, however, the operating times are comparable to elective open infrarenal aneurysms repairs. This can be explained by the low prevalence of infectious causes in this series and the major role of open aortic surgery in this center. These results are concordant with large series from other highvolume aortic centers. ${ }^{19,20}$

Specifically, the early mortality (12.9\%) in this series is perfectly comparable to other large cohorts ${ }^{9,21}$ and major meta-analyzes, ${ }^{22,23}$ which reported rates of $9 \%$ to $17 \%$. Of note, the early $2.9 \%$ and estimated $71 \% 5$-year mortality rate for elective late open conversion is comparable to the results for primary infrarenal AAA repair in the literature. ${ }^{24}$ Morbidity, mainly due to $A K I$ and intestinal ischemia, predominated after emergent surgery.

In the largest and most recent meta-analysis, Goudeketting et $\mathrm{al}^{25}$ reported a 10 times higher 30-day mortality rate for patients treated with late open conversion in an urgent vs elective setting. With $41.7 \%$ early deaths in patients undergoing extreme emergent conversion, the results reported here are consistent with meta-analysis targeting this population. ${ }^{26}$ The treatment of an infected 


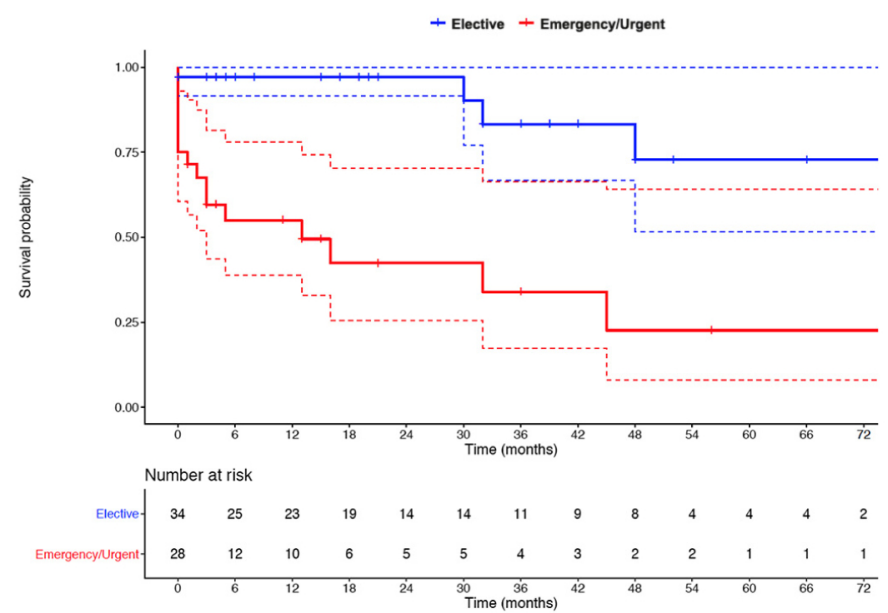

Fig. Kaplan-Meier estimated survival of patients according to emergency/urgent vs elective status.

EVAR is a specific entity that requires precise and early management. As mentioned by Chaufour et al, ${ }^{27}$ this unit also performs as quickly as possible investigations including biology, blood cultures, and imaging (computed tomography angiography scan, white blood cell scan). To treat this pathologic process, complete stent graft explantation and a direct reconstruction in situ at the same time with arterial allografts or, more recently, physician-made xenopericardial grafts are preferred in the study unit.

The occurrence of late post-EVAR rupture is a consequence not only of EVAR and endograft failure but also of surveillance. Mehta et $\mathrm{al}^{28}$ demonstrated that lack of compliance was a factor in $74 \%$ of patients presenting with post-EVAR rupture. Rigorous and lifelong followup after EVAR is thus recommended by most authors. $22,26,29.30$ The results of this study clearly demonstrate that excellent early and long-term results can be achieved in elective patients. Whereas this reinforces the need for early detection and management of endograft failure, there is equipoise in the literature, with societal guidelines recommending rigorous surveillance $e^{3,31}$ but meta-analysis suggesting that compliance increases reintervention but not survival. ${ }^{32}$ One interpretation of the favorable results of this study is that reintervention for a failing endograft is challenging and the management of those requiring intervention should therefore be centralized into high-volume aortic units. In this study, the increasing number of conversions from 2015 to the present is notable, which can be explained by several reasons. First, there is a unit trend to practice open conversions earlier than before because secondary endovascular procedures for endoleaks offer disappointing results. ${ }^{19,33}$ This period also corresponds to the designation of this high-volume unit (more than at least 60 juxtarenal or infrarenal aortic aneurysm repairs per year for 22 years) as an aortic center, thereby increasing the number of external referrals.
Finally, it has become common practice for many centers to perform EVAR outside the instructions for use and for younger patients, increasing the probability of endograft failure. The controversial UK National Institute for Health and Care Excellence consultation document suggests that use of EVAR should be highly restricted. If the recommendations are implemented, the number of reinterventions may yet again decrease. ${ }^{34}$

Limitations. The limits of this study are defined by its retrospective and single-center design. Only $40 \%$ of our late open surgical conversions were for patients originally treated in our unit. Thus, as in other studies on this subject, the incidence of late open conversion after EVAR cannot be precisely determined. Similarly, the proportion of patients who have had EVAR outside of instructions for use remains uncertain.

\section{CONCLUSIONS}

Late open surgical conversion is associated with acceptable perioperative risk when it is performed in a highvolume open aortic center. Elective late open conversion is compared with emergent, associated with a significant reduction in morbidity and mortality. Except in cases of infection, partial or complete preservation of the endograft reduces perioperative morbidity. Long-term followup and surveillance of patients undergoing open conversion of EVAR, even after partial or complete preservation of the endograft, suggest that it is a safe and reliable strategy with outcomes comparable to primary repair.

\section{AUTHOR CONTRIBUTIONS}

Conception and design: RC, LC, PAI

Analysis and interpretation: RC, LC, BO, NM, CMA, PAI

Data collection: RC, LC, PAU, EP, PB, PAI

Writing the article: RC, LC, PAI

Critical revision of the article: $L C, B O, P A u, N M, E P, P B$, CMA, PAI

Final approval of the article: RC, LC, BO, PAu, NM, EP, PB, CMA, PAI

Statistical analysis: BO, PAu, NM

Obtained funding: Not applicable

Overall responsibility: PAI

\section{REFERENCES}

1. Powell JT, Sweeting MJ, Ulug P, Blankensteijn JD, Lederle FA, Becquemin JP, et al. Meta-analysis of individual-patient data from EVAR-1, DREAM, OVER and ACE trials comparing outcomes of endovascular or open repair for abdominal aortic aneurysm over 5 years. Br J Surg 2017;104:166-78.

2. Patel SR, Allen C, Grima MJ, Brownrigg JR, Patterson BO, Holt PJ, et al. A systematic review of predictors of reintervention after EVAR: guidance for risk-stratified surveillance. Vasc Endovascular Surg 2017:51:417-28.

3. Chaikof EL, Dalman RL, Eskandari MK, Jackson BM, Lee WA, Mansour MA, et al. The Society for Vascular Surgery practice guidelines on the care of patients with an abdominal aortic aneurysm. J Vasc Surg 2018;67:2-77.e2 
4. Thomas ME, Blaine C, Dawnay A, Devonald MA, Ftouh S, Laing $\mathrm{C}$, et al. The definition of acute kidney injury and its use in practice. Kidney Int 2015;87:62-73.

5. Chen CF, Lin YC, Tsai HL, Huang CW, Yeh YS, Ma CJ, et al. Short- and long-term outcomes of laparoscopic-assisted surgery, mini-laparotomy and conventional laparotomy in patients with stage I-III colorectal cancer. J Minim Access Surg 2018;14:321-34.

6. May J, White GH, Yu W, Waugh R, Stephen M, Sieunarine K, et al. Conversion from endoluminal to open repair of abdominal aortic aneurysms: a hazardous procedure. Eur J Vasc Endovasc Surg 1997;14:4-11.

7. Harris PL, Vallabhaneni SR, Desgranges P, Becquemin JP, van Marrewijk C, Laheij RJ. Incidence and risk factors of late rupture, conversion, and death after endovascular repair of infrarenal aortic aneurysms: the EUROSTAR experience. European Collaborators on Stent/graft techniques for aortic aneurysm repair. J Vasc Surg 2000;32:739-49.

8. Kelso RL, Lyden SP, Butler B, Greenberg RK, Eagleton MJ, Clair DG. Late conversion of aortic stent grafts. J Vasc Surg 2009;49:589-95.

9. Turney EJ, Steenberge SP, Lyden SP, Eagleton MJ, Srivastava SD, Sarac TP, et al. Late graft explants in endovascular aneurysm repair. J Vasc Surg 2014;59:886-93.

10. Gambardella I, Blair PH, McKinley A, Makar R, Collins A, Ellis PK, et al. Successful delayed secondary open conversion after endovascular repair using partial explantation technique: a single-center experience. Ann Vasc Surg 2010;24:646-54.

11. Steenberge SP, Lyden SP, Turney EJ, Kelso RL, Srivastava SD, Eagleton MJ, et al. Outcomes after partial endograft explantation. Ann Vasc Surg 2016:31:1-7.

12. McManus C, Loan W, Lee B, Blair P, Harkin D. Late aneurysm rupture after delayed secondary open conversion with partial explantation for failed endovascular repair. J Vasc Surg 2016:63:234-6.

13. Arnaoutakis DJ, Sharma C, Blackwood S, Shah SK, Menard M, Ozaki CK, et al. Strategies and outcomes for aortic endograft explantation. J Vasc Surg 2019;69:80-5.

14. Scali ST, McNally MM, Feezor RJ, Chang CK, Waterman AL, Berceli SA, et al. Elective endovascular aortic repair conversion for type la endoleak is not associated with increased morbidity or mortality compared with primary juxtarenal aneurysm repair. J Vasc Surg 2014;60:286-94.e1.

15. Mangialardi N, Ronchey S, Orrico M, Serrao E, Alberti V, Fazzini S, et al. Surgical conversion with graft salvage as a definitive treatment for persistent type II endoleak causing sac enlargement. J Vasc Surg 2015;62:1437-41.

16. Klonaris C, Lioudaki S, Katsargyris A, Psathas E, Kouvelos C, Doulaptsis $\mathrm{M}$, et al. Late open conversion after failed endovascular aortic aneurysm repair. J Vasc Surg 2014;59:291-7.

17. Ultee KH, Soden PA, Zettervall SL, Darling J, Verhagen HJ, Schermerhorn ML. Conversion from endovascular to open abdominal aortic aneurysm repair. J Vasc Surg 2016;64: 76-82.

18. Bonvini S, Wassermann V, Menegolo M, Scrivere P, Grego F, Piazza M. Surgical infrarenal "neo-neck" technique during elective conversion after EVAR with suprarenal fixation. Eur J Vasc Endovasc Surg 2015;50:175-80.

19. Mohapatra A, Robinson D, Malak O, Madigan MC, Avgerinos ED, Chaer RA, et al. Increasing use of open conversion for late complications after endovascular aortic aneurysm repair. J Vasc Surg 2019;69:1766-75.

20. Wu Z, Xu L, Qu L, Raithel D. Seventeen years' experience of late open surgical conversion after failed endovascular abdominal aortic aneurysm repair with 13 variant devices. Cardiovasc Intervent Radiol 2015;38:53-9.
21. Ben Abdallah I, El Batti S, Abou-Rjeili M, Fabiani JN, Julia P, Alsac JM. Open conversion after endovascular abdominal aneurysm repair: an 8 year single centre experience. Eur $\mathrm{J}$ Vasc Endovasc Surg 2017;53:831-6.

22. Moulakakis KG, Dalainas I, Mylonas S, Giannakopoulos TC, Avgerinos ED, Liapis CD. Conversion to open repair after endografting for abdominal aortic aneurysm: a review of causes, incidence, results, and surgical techniques of reconstruction. J Endovasc Ther 2010;17:694-702.

23. Kouvelos C, Koutsoumpelis A, Lazaris A, Matsagkas M. Late open conversion after endovascular abdominal aortic aneurysm repair. J Vasc Surg 2015;61:1350-6.

24. Bahia SS, Holt PJ, Jackson D, Patterson BO, Hinchliffe RJ, Thompson MM, et al. Systematic review and meta-analysis of long-term survival after elective infrarenal abdominal aortic aneurysm repair 1969-2011: 5 year survival remains poor despite advances in medical care and treatment strategies. Eur J Vasc Endovasc Surg 2015;50:320-30.

25. Goudeketting SR, Fung Kon Jin PH, Ünlü Ç, de Vries JP. Systematic review and meta-analysis of elective and urgent late open conversion after failed endovascular aneurysm repair. J Vasc Surg 2019;70:615-28.e7.

26. Antoniou GA, Georgiadis GS, Antoniou SA, Neequaye S, Brennan JA, Torella F, et al. Late rupture of abdominal aortic aneurysm after previous endovascular repair: a systematic review and meta-analysis. J Endovasc Ther 2015;22:734-44.

27. Chaufour X, Gaudric J, Goueffic Y, Khodja RH, Feugier P, Malikov S, et al. A multicenter experience with infected abdominal aortic endograft explantation. J Vasc Surg 2017;65:372-80.

28. Mehta M, Sternbach Y, Taggert JB, Kreienberg PB, Roddy SP Paty PS, et al. Long-term outcomes of secondary procedures after endovascular aneurysm repair. J Vasc Surg 2010;52:1442-9.

29. Verzini F, Isernia C, De Rango P, Simonte C, Parlani G, Loschi D, et al. Abdominal aortic endografting beyond the trials: a 15year single-center experience comparing newer to older generation stent-grafts. J Endovasc Ther 2014;21:439-47.

30. Millon A, Deelchand A, Feugier P, Chevalier JM, Favre JP; University Association for Research in Vascular Surgery (AURC). Conversion to open repair after endovascular aneurysm repair: causes and results. A French multicentric study. Eur J Vasc Endovasc Surg 2009;38:429-34.

31. Wanhainen A, Verzini F, Van Herzeele I, Allaire E, Bown M, Cohnert T, et al. Editor's choice-European Society for Vascular Surgery (ESVS) 2019 clinical practice guidelines on the management of abdominal aorto-iliac artery aneurysms. Eur J Vasc Endovasc Surg 2019;57:8-93.

32. Crima MJ, Boufi M, Law M, Jackson D, Stenson $K$, Patterson B, et al. Editor's choice-the implications of noncompliance to endovascular aneurysm repair surveillance: a systematic review and meta-analysis. Eur J Vasc Endovasc Surg 2018:55:492-502.

33. Ultee $\mathrm{KH}$, Büttner $\mathrm{S}$, Huurman R, Bastos Conçalves $\mathrm{F}$, Hoeks SE, Bramer WM, et al. Systematic review and metaanalysis of the outcome of treatment for type II endoleak following endovascular aneurysm repair. Eur J Vasc Endovasc Surg 2018;56:794-807.

34. Abdominal aortic aneurysm: NICE guideline. Draft guidance consultation (May 2018). Available at: https://www.nice.org.uk/ guidance/ng156/documents/short-version-of-draft-guideline. Accessed May 16, 2018. 
Supplementary Table I (online only). Demographic data of patients

\begin{tabular}{lc}
\hline Comorbidities & \\
\hline Smoking history & $37(59.7)$ \\
\hline Hypertension & $54(87.1)$ \\
\hline Dyslipidemia & $41(66.1)$ \\
\hline Diabetes mellitus & $9(14.5)$ \\
\hline COPD & $8(12.9)$ \\
\hline FEV ${ }_{1}$, L & $2.32( \pm 0.59)$ \\
\hline Coronary heart disease & $29(46.8)$ \\
\hline Dysrhythmia & $16(25.8)$ \\
\hline LVEF, \% & $59( \pm 8.4)$ \\
\hline Chronic renal insufficiency & $27(43.6)$ \\
\hline Preoperative serum creatinine, mmol/L & $95.6( \pm 33.5)$ \\
\hline BMI, kg/m ${ }^{2}$ & $26.5( \pm 3.5)$ \\
\hline Previous abdominal surgery & $26(41.9)$ \\
\hline ASA class & \\
\hline 1 & $10(16.4)$ \\
\hline 2 & $31(50.8)$ \\
\hline 3 & $15(24.6)$ \\
\hline 4 & $5(8.2)$ \\
\hline 5 & $3.3 \pm 0.8$ \\
\hline Mean \pm SD & \\
\hline ASA. American Society of Anesthesiologists; BMI, body & mass index; \\
COPD, chronic obstructive pulmonary disease; FEV, forced expiratory \\
volume in 1 second; LVEF, left ventricular ejection fraction; SD, standard \\
deviation. \\
Categorical variables are presented as number (\%). Continuous vari- \\
ables are presented as mean \pm standard deviation.
\end{tabular}

Supplementary Table II (online only). Death within 30 days

\begin{tabular}{llllllc}
\hline No. & Age, years & $\begin{array}{c}\text { Stent graft } \\
\text { fixation }\end{array}$ & \multicolumn{1}{c}{ Indications } & Level of emergency & Mode of death & $\begin{array}{c}\text { Postoperative day } \\
\text { of death }\end{array}$ \\
\hline 1 & 83 & Suprarenal & Type II and III endoleaks & Elective & Cardiac failure & 3 \\
\hline 2 & 93 & Suprarenal & Rupture/type IA endoleak & Extreme emergency & Hemorrhagic shock & 1 \\
\hline 3 & 87 & Suprarenal & Rupture/type IB endoleak & Extreme emergency & Hemorrhagic shock & 0 \\
\hline 4 & 89 & Suprarenal & Infection/type IB endoleak & Extreme emergency & Multiple organ failure & 7 \\
\hline 5 & 74 & Infrarenal & Rupture/type V endoleak & Extreme emergency & Multiple organ failure & 1 \\
\hline 6 & 78 & Suprarenal & Rupture/type IA endoleak & Extreme emergency & Multiple organ failure & 3 \\
\hline 7 & 93 & Infrarenal & Type IB endoleak & Urgent & Multiple organ failure & 7 \\
\hline 8 & 79 & Suprarenal & Type IA and II endoleaks & Urgent & Intestinal ischemia & 9 \\
\hline
\end{tabular}

